\title{
High Strain Rate Response of Adhesively Bonded Fiber-Reinforced Composite Joints - A Computational Study to Guide Experimental Design
}

\author{
Suraj Ravindran ${ }^{a, b}$, Subramani Sockalingam ${ }^{\text {a,b,c }}$, Addis Kidane ${ }^{a, b}$, \\ Michael Sutton ${ }^{\text {a,b,d }}$, Brian Justusson ${ }^{\mathrm{e}}$, Jenna Pang ${ }^{\mathrm{e}}$ \\ ${ }^{a}$ Department of Mechanical Engineering, University of South Carolina, USA \\ ${ }^{b}$ McNAIR Center for Aerospace Innovation and Research, University of South Carolina, USA \\ ${ }^{c}$ SmartState Center for Multifunctional Materials and Structures, University of South Carolina, USA \\ ${ }^{d}$ SC State Center for Mechanics, Materials and NDE, University of South Carolina, USA \\ ${ }^{e}$ Boeing Research \& Technologies, USA
}

\begin{abstract}
Adhesively bonded carbon fiber-reinforced epoxy composite laminates are widely used in aerospace applications. During a high energy impact event, these laminates are often subjected to high strain rate loading. However, the influence of high strain rate loading on the response of these composite joints is not well understood. Computational finite element (FE) modeling and simulations are conducted to guide the design of high strain rate experiments. Two different experimental designs based on split Hopkinson bar were numerically modeled to simulate Mode I and Mode II types loading in the composite. In addition, the computational approach adopted in this study helps in understanding the high strain rate response of adhesively bonded composite joints subjected to nominally Mode I and Mode II loading. The modeling approach consists of a ply-level 3D FE model, a progressive damage constitutive model for the composite material behavior and a cohesive tie-break contact element for interlaminar delamination.
\end{abstract}

Keywords: composite, adhesive joint, fracture, Mode I, Mode II

\section{Introduction}

Adhesively bonded composite joints are widely used in aerospace structures that could be subjected to high energy dynamic impact events such as fan blade out, open rotor, etc. While these joints are generally designed to induce first ply failure, the mechanical performance may vary greatly under dynamic loading as a result of strain rate dependency in the adhesive. Strain rate dependence could include adhesive strength, adherent (composite)-adhesive interface properties and composite properties. A validated computational approach is essential to predict the response of the bonded joints at different loading rates. Therefore, experimental characterization of such joints is essential for understanding the response and to validate the computational models; however, elevated loading rate experiments to characterize the bonded joint behavior are scarce. Advent of digital image correlation paves the ways to extract the crack tip opening displacement (CTOD) using images captured during deformation [1]. The calculation of CTOD helps in estimating the effective energy release rate during bonded joint failure. Designing an experimental setup to load the sample in pure Mode I/ Mode II is still challenging. Therefore, the objective of this study is to numerically investigate the Mode-I and Mode-II type of elevated loading rate in composite bonded joints. This study also helps in finding an optimal experimental design that can be used to validate the modeling approach at different strain rates.

\section{Material and Methods}

\section{Mode I and Mode II loading configuration}

Mode I (opening) and II (sliding) loading configurations in this numerical study are shown in Fig.1. In samples for the Mode I type of loading, a precrack of length 'a' was used as shown in Fig.1a. This approach is similar to what has been proposed by Thorsson [2]. Thorsson used a drop weight impact tower and standard Double Cantilevered Beam (DCB) type specimens to determine the dynamic response for delamination. This approach was investigated numerically and determined to have limitations in examining a range of loading rates. At higher loading rates, the fixture became unstable resulting in loss of contact with the loading pins. This led toward a technical path of performing the test using tradition Split Hopkinson Pressure Bar (SHPB) techniques. A SHPB with a modified end with a wedge that drives through the sample is considered. Due to the complex nature of loading, the effects of wedge angle, pre-crack length and theusage of transmitting bar versus load cell were numerically investigated. Two wedge 
angles $\left(60^{\circ}\right.$ and $\left.90^{\circ}\right)$ were considered to understand the effect of wedge angle on the loading. The wedge was pushed into a symmetric triangular notch present at the left edge of the precrack, see Fig.1a. The objective was to obtain the best loading configuration and measurement technique for the experiment, therefore two types of load measurement at the support end of the sample was investigated in this study. In first modeling approach, a transmitter bar was modeled, whereas, in the second, boundary conditions for a load cell was used. In case of Mode II loading, a sample fixture that are typically used for 3-point bend loading was used as shown in Fig.1c. The span of the support end was chosen to be 2". The diameter of the semi-circular nose tip was $6.25 \mathrm{~mm}$.

a)
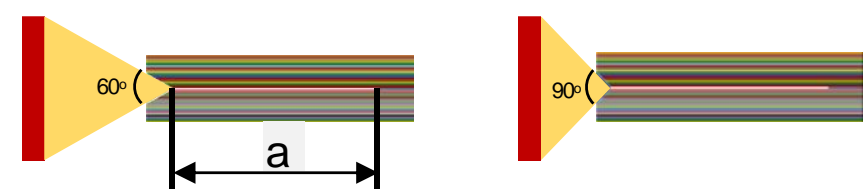

b)
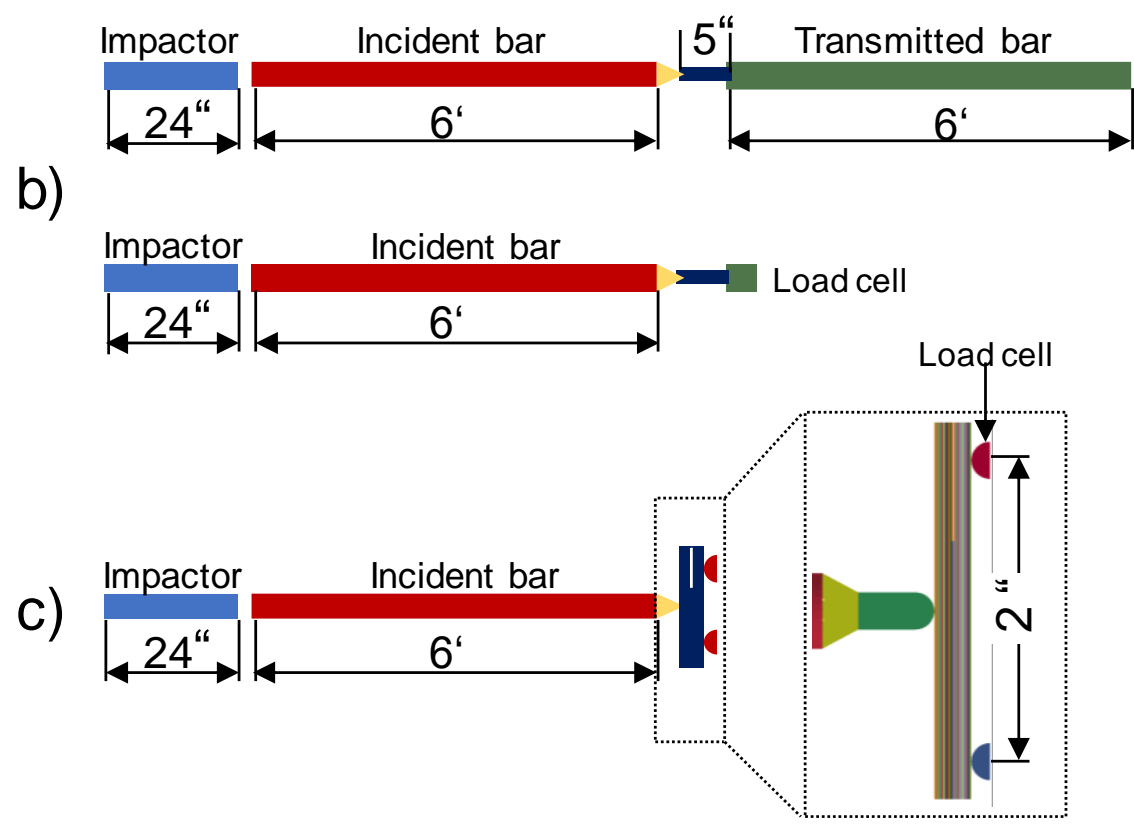

Fig. 1 a) The wedge angle used for the Mode I loading, b) Loading configuration for Mode I, c) loading configuration of Mode II experiments.

The Mode I and Mode II model uses a ply-level model with one solid element per ply along the thickness. The composite material (IM7/8552) behavior was captured with progressive damage analysis (PDA) using LS-DYNA material model MAT 162 [3]. The material model for MAT 162 is capable of modeling tension, compression and shear modes of failure in the material. A quasi-isotropic layup [45/90/-45/0 $]_{2 s}$ is used for the laminates. The plies were modeled as 0.0072 " thick and the adhesive was modeled as 0.008 " thick. The adhesive was modeled as isotropic elastic-plastic using data for FM 300-2 [4]. Element erosion for the adhesive was not turned on. The adhesive-adherend interface was captured with tiebreak between the FM300-2 and adjacent ply and there was tiebreak between all plies to model delamination. The properties of the composite laminates and the interface between the composite plies are obtained from the previous phase of this project as part of the Advanced Composites Consortium (ACC) [5]. The fracture toughness between the adhesive and composite is assumed to be higher than the fracture toughness between the composite plies [6]. The Hopkinson bar of 0.5 in diameter was modeled as aluminum and the analysis was performed for $5 \mathrm{~m} / \mathrm{s}$ and $10 \mathrm{~m} / \mathrm{s}$ striker bar impacts. 


\section{Results and Discussion}

\section{Mode I loading}

Fig. 2 shows the incident and transmitter bar signal obtained for a striker impact velocity of $10 \mathrm{~m} / \mathrm{s}$ in the $60^{\circ}$ wedge experiment simulation. It shows that the transmitted signals are very weak due to impedance mismatch of the specimen and the bar. Measurement of such a low strain signal using strain gage is difficult, therefore, a load cell at the support end is preferable for the experiments to get a reliable force measurement.

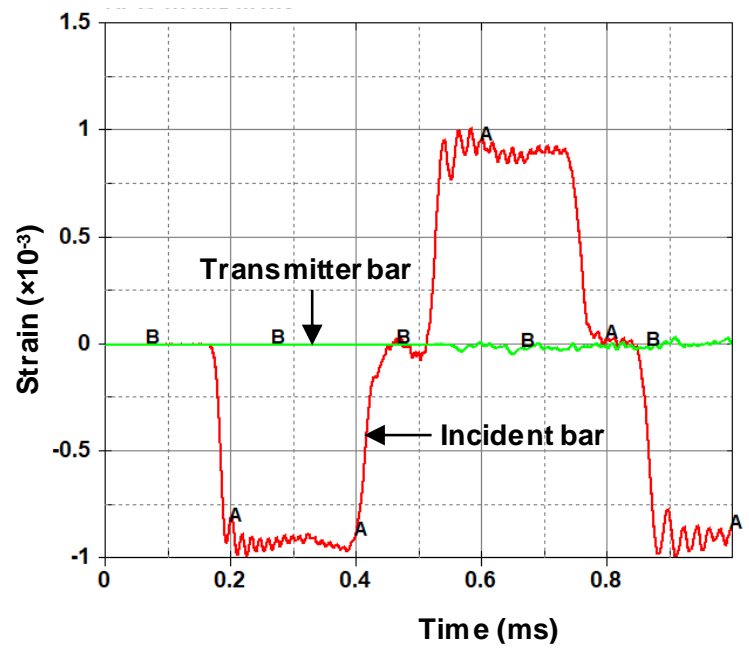

Fig. 2 a) The wedge angle used for the Mode I loading, b) Loading configuration for Mode I, c) loading configuration of Mode II experiments.

A striker bar length of 24 " is chosen such that specimen failure is achieved during the first pulse. Forces at the contact between the $60^{\circ}$ wedge and the specimen were collected for a $5 \mathrm{~m} / \mathrm{s}$ striker velocity. Figure 3 shows the axial and shear forces as measured by the load cell and transmitter bar setups. Time zero corresponds to the time of striker bar impact. Crack initiation was occurred at $140 \mu$ s after the start of the loading of the sample. The pre-test prediction results indicate no significant difference between the loads measured at the contact between specimen and load cell or transmitted bar.
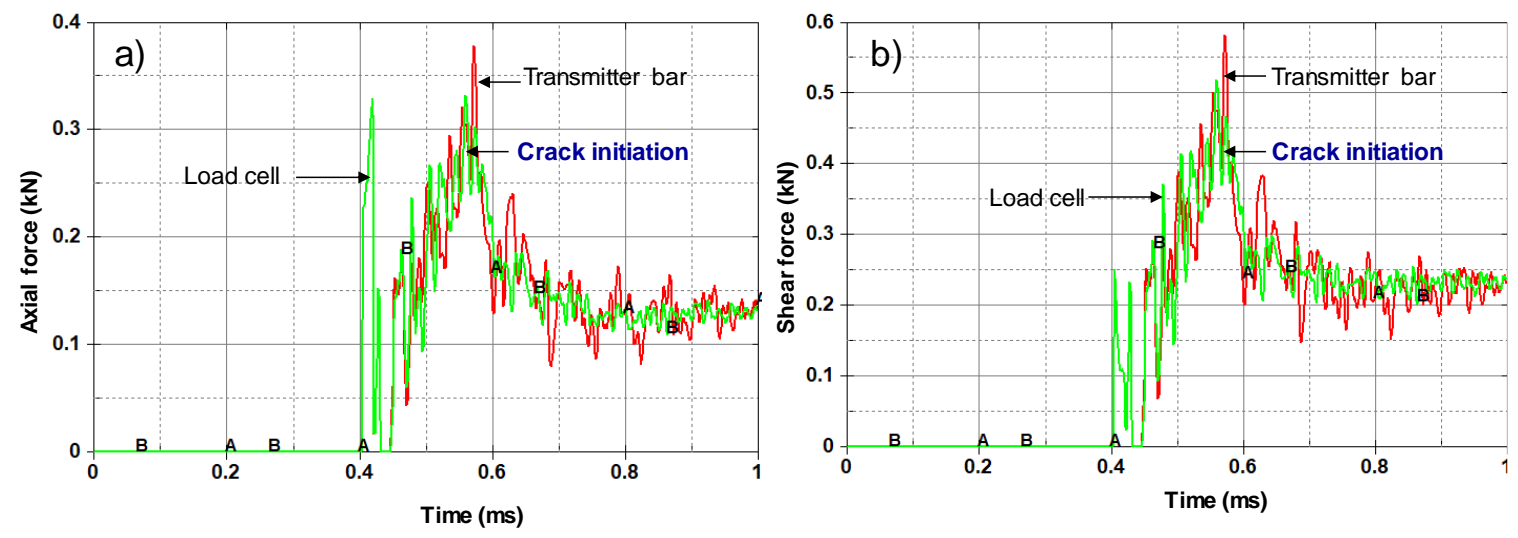

Fig. 3. Forces at the contact between the $60^{\circ}$ wedge and the specimen; a) shows the axial forces as measured by the load cell and transmitter bar, b) shows the shear forces as measured by the load cell and transmitter bar. 
The initial test setup used a $60^{\circ}$ wedge on the incident bar. In the interest of exploring other potential wedge angles, the end wedge geometry was investigated with a $20 \mathrm{~mm}$ precrack in two configurations: a $60^{\circ}$ wedge and a $90^{\circ}$ wedge. It should be noted here that the study was performed for a striker velocity of $5 \mathrm{~m} / \mathrm{s}$. Figure 4 shows the Mode I/Mode II failure data for the two configurations. Mode I and Mode II fracture energy was high in the $90^{\circ}$ wedge compared to the $60^{\circ}$ wedge loading. In addition, the $90^{\circ}$ wedge resulted in increased Mode II content of fracture energy dissipated in the interface between the plies. The Mode II content of fracture energy in the $90^{\circ}$ wedge was close to $30 \%$ of the Mode I fracture energy. Whereas in the $60^{\circ}$ wedge, the Mode II component was less than $10 \%$ of the Mode I component. The final goal of this experimental configuration is to validate the Mode I failure, therefore, it was recommended to use the $60^{\circ}$ end wedge over the $90^{\circ}$ wedge.
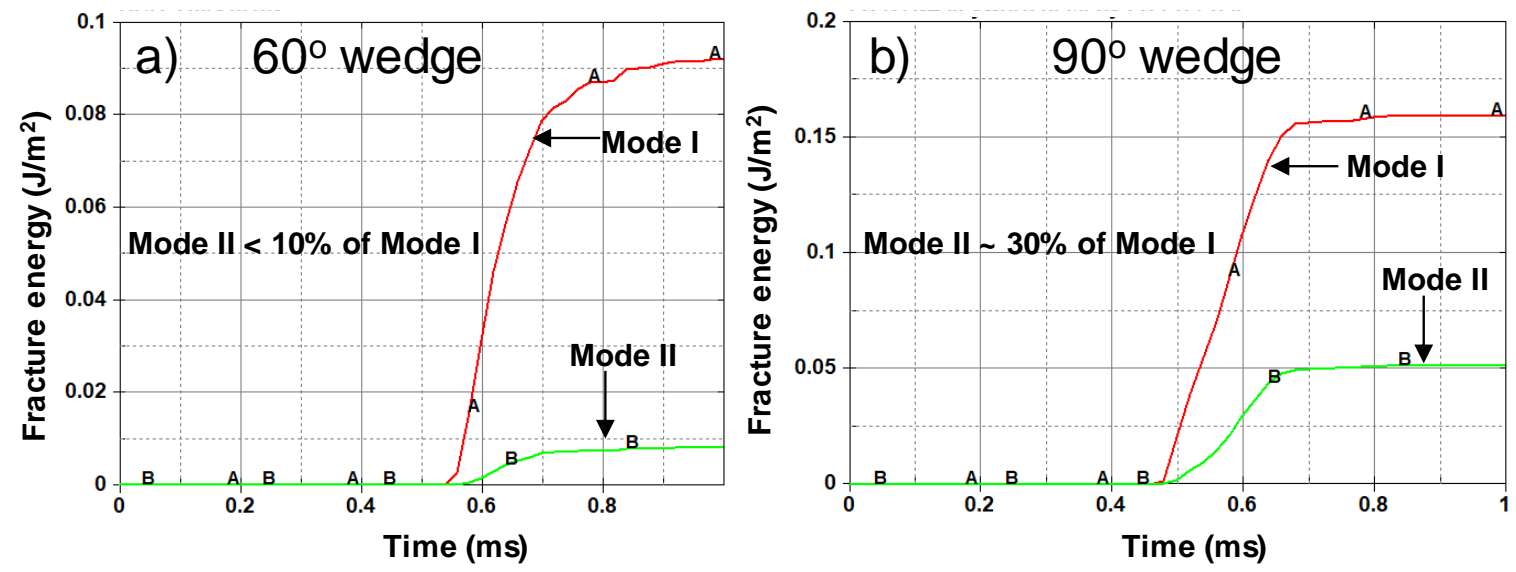

Fig. 4 Fracture energy dissipated at the interface; a) fracture energy and the relative contribution of Mode I and Mode II fracture energy in $60^{\circ}$ wedge, $\mathrm{b}$ fracture energy and the relative contribution of Mode I and Mode II fracture energy in $90^{\circ}$ wedge.

Finally, the Mode I model was used to evaluate the influence of the precrack length on crack growth. Using the $60^{\circ}$ wedge, two precrack lengths were considered: $20 \mathrm{~mm}(0.787 \mathrm{in}$.) crack and $10 \mathrm{~mm}(0.394 \mathrm{in})$. Measuring the crack growth during the first incident pulse, the longer precrack $(20 \mathrm{~mm})$ produced much less crack growth of $8 \mathrm{~mm}(0.315$ in.) compared to the $20 \mathrm{~mm}$ crack growth seen with the $10 \mathrm{~mm}$ precrack length. These results illustrate that a shorter precrack is the preferred option for this experiment as it provided greater crack growth than a long precrack. In all of the DCB studies, delamination between the first ply $\left(45^{\circ}\right)$ and second ply $\left(90^{\circ}\right)$ is predicted as the dominant deformation mechanism as shown in Figure 5.

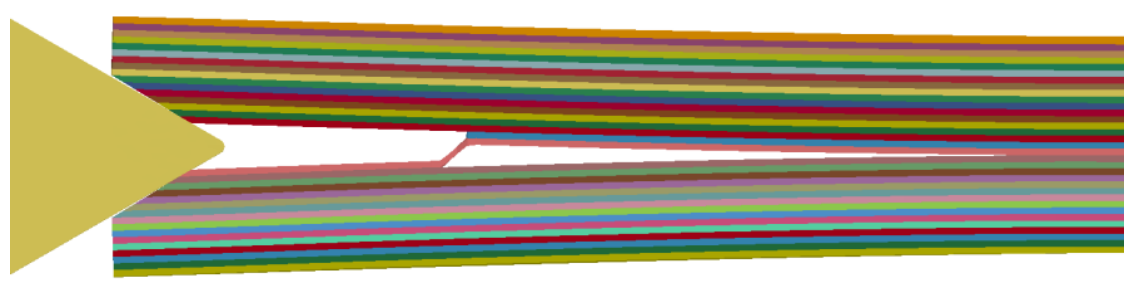

Fig. 5 Delamination in Mode I 


\section{Mode II loading}

The interfaces between the plies are marked using If-5 $\left(45^{\circ}: 90^{\circ}\right)$, If- $6\left(90^{\circ}:-45^{\circ}\right)$, If- $9\left(45^{\circ}: 90^{\circ}\right)$ and If- $18\left(-45^{\circ}\right.$ : $90^{\circ}$ ) as shown in Fig.6a. Total fracture energy dissipated at different interfaces for a striker velocity of $10 \mathrm{~m} / \mathrm{s}$ is plotted in Fig.6b. It shows that the fracture initiates (delamination) at the interface 'If- 6 ' before the failure of other interfaces, which indicates that the interface between $90^{\circ}$ and $-45^{\circ}$ is the critical location in the composite. The crack initiation occurs at approximately $500 \mu$ s after impact loading as shown Fig.6a.

In order to calculate the contribution of Mode I and Mode II components in the total energy dissipated at the interface, failure mode data was tracked at this interface, "If-6", see Fig.6c. The fracture energy associated with the Mode II was seen to be very close to the total fracture energy at the interface 'If- 6 '. Therefore, the amount of Mode I fracture energy was negligible which indicates that the specimen demonstrated predominantly Mode II crack growth. This result suggests that the test design is meeting test goals by generating primarily Mode II failure for the validation efforts.

a)
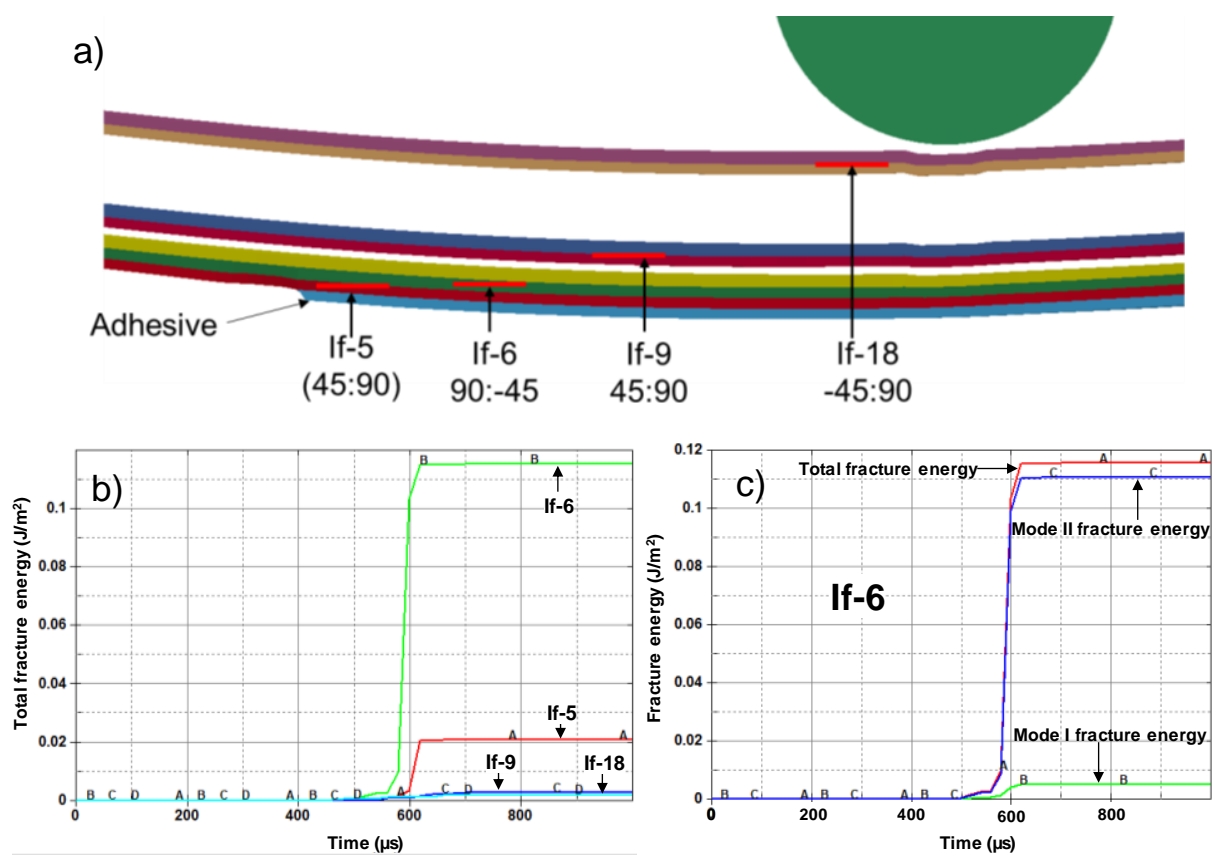

Fig. 6 a) Laminate interactions under incident bar nose as tracked at several ply-to-ply interfaces as identified, b) total fracture energy at different interfaces with time, c) fracture energy at the interface If- 6 .

Figure 7 shows the predicted delamination of interface, "If-6", at approximately $600 \mu \mathrm{s}$. Blue areas in the model indicate the region is still bonded, red areas indicate a total disbond per the nodal contact gap. This data was produced an estimated $100 \mu \mathrm{s}$ after the initial delamination, the crack speed was estimated to be $350 \mathrm{~m} / \mathrm{s}$ based on the model output every $20 \mu \mathrm{s}$. 


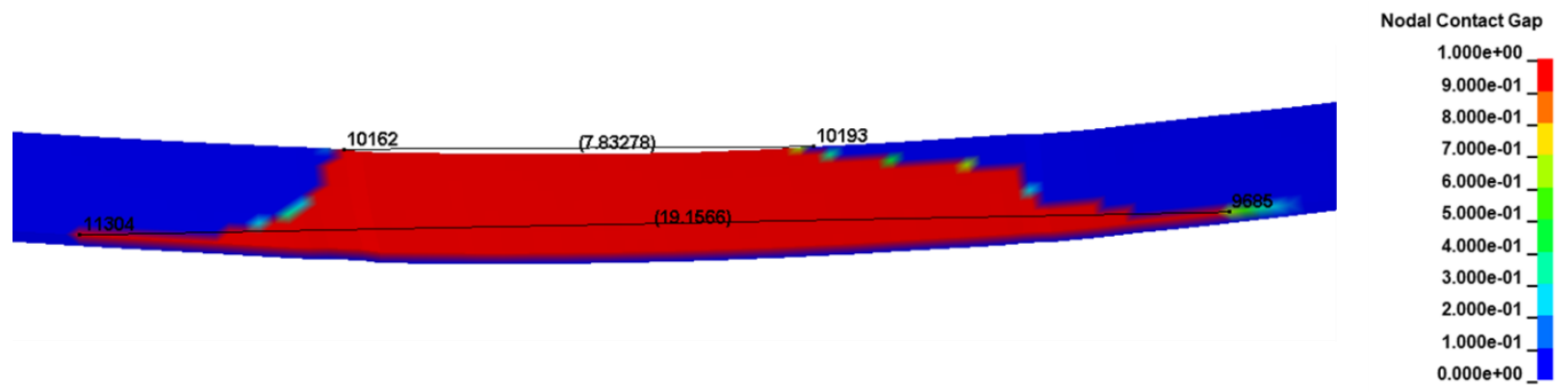

Fig. 7 Delamination at interface "If-6" between the $90^{\circ}$ and $-45^{\circ}$ plies at approximately $600 \mu$ s.

For the $10 \mathrm{~m} / \mathrm{s}$ and $15 \mathrm{~m} / \mathrm{s}$ events, the predominant delamination is predicted to occur at the interface between the $90^{\circ}$ and $-45^{\circ}$ plies. There is also the potential for adhesive failure. Fig. 8 shows the adhesive deformation through effective plastic strain. Calculating the shear strain with $\varepsilon=\gamma / \sqrt{ } 3$ indicates a maximum shear strain value of approximately 0.35 . Per Error! Reference source not found., RT FM 300-2 has an ultimate shear strain of approximately 0.2 [4] which indicates that the adhesive will likely fail at the documented strain rates.

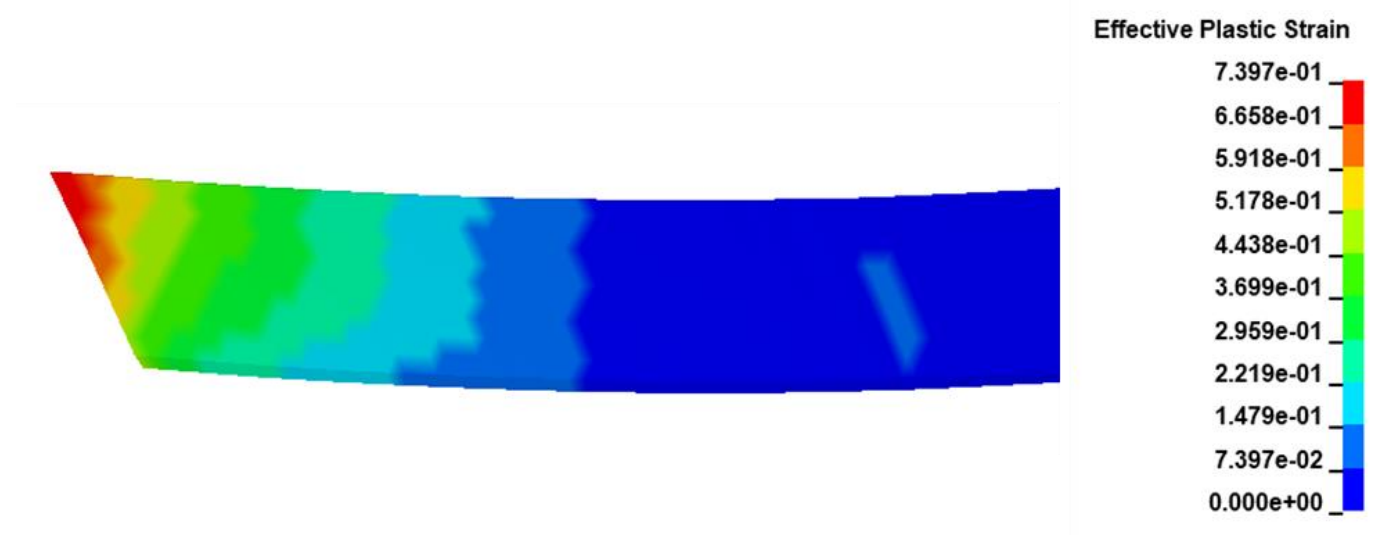

Fig. 8 Effective plastic strain contours of adhesive at $620 \mu \mathrm{s}$

\section{Summary}

A numerical investigation was performed to find an optimal experimental design for Mode I and Mode II fracture characterization and understand the possible failure modes in the composite bonded joint using IM7/8552 and epoxybased film adhesive. The conclusions from the study is as follows,

- Mode I loading shows that the load cells are suitable to measure the support end load compare to transmitter bar.

- Shorter precrack is suitable for obtaining longer crack growth.

- The $60^{\circ}$ wedge loading shows a lower Mode II component, therefore $60^{\circ}$ wedge is preferable for the Mode I type of loading.

- Mode II setup shows a very negligible component Mode I in the total fracture energy dissipated at the interface.

- Mode II simulations show a possible adhesive failure during dynamic loading.

Future work includes conducting experiments based on these pre-test predictions to validate the modeling approach.

\section{Acknowledgements}

The material is based upon work supported by NASA under Award No. NNL09AA00A. Any opinions, findings, and conclusions or recommendations expressed in this material are those of the author(s) and do not necessarily reflect the views of the National Aeronautics and Space Administration. 


\section{References}

1. Nunes LCS, Reis JML (2012) Estimation of crack-tip-opening displacement and crack extension of glass fiber reinforced polymer mortars using digital image correlation method. Mater Des 33:248-253

2. Thorsson SI, Waas AM, Schaefer J, et al (2018) Effects of elevated loading rates on mode I fracture of composite laminates using a modified wedge-insert fracture method. Compos Sci Technol 156:39-47 . doi: 10.1016/j.compscitech.2017.12.018

3. Yen CF (2012) A ballistic material model for continuous-fiber reinforced composites. Int J Impact Eng 46:11-22 . doi: 10.1016/j.ijimpeng.2011.12.007

4. Wang CH, Gunnion AJ (2008) On the design methodology of scarf repairs to composite laminates. Compos Sci Technol 68:35-46

5. Hunziker KJ, Pang J, Pereira M, et al (2018) NASA ACC High Energy Dynamic Impact Methodology and Outcomes. In: 2018 AIAA/ASCE/AHS/ASC Structures, Structural Dynamics, and Materials Conference. American Institute of Aeronautics and Astronautics

6. Mohan J, Ivanković A, Murphy N (2014) Mode i fracture toughness of co-cured and secondary bonded composite joints. Int J Adhes Adhes 51:13-22 . doi: 10.1016/j.ijadhadh.2014.02.008 